\title{
Novel nonlinear control structure for vector control of SPIM drive using BS PCH
}

\author{
Ngoc Thuy Pham \\ Department of Electrical Engineering Technology, Industrial University of Ho Chi Minh City, Vietnam
}

\begin{tabular}{|c|c|}
\hline Article Info & ABSTRACT \\
\hline Article history: & This paper presents a novel structure combining the port-controlled \\
\hline Received Apr 5, 2019 & Hamiltonian $(\mathrm{PCH})$ and Backstepping (BS) nonlinear control for the vector \\
\hline Revised Dec 26, 2019 & improve the outer loop's robustness, the BS technique using the integral \\
\hline Accepted Jan 28, 2020 & tracking errors action is proposed in the speed and flux controllers design. \\
\hline Keywords: & $\begin{array}{l}\text { The advantage of this proposed control law is not to increase the complexity } \\
\text { of differential equation resolution due to being not increased system states } \\
\text { numbers. To enhance more the performance of SPIM drives (SPIMD), port- }\end{array}$ \\
\hline Backstenning control & controlled Hamiltonian $(\mathrm{PCH})$ scheme is used in the inner current loop \\
\hline High accuracy & controllers. In this proposed PCH current controller, the stabilization of \\
\hline Nonlinear control & $\begin{array}{l}\text { controller is achieved via system passivity. In that, the interconnection and } \\
\text { damping matrix functions of PCH svstem are shaped so that the physical }\end{array}$ \\
\hline Port controled hamiltinian & (Hamiltonian) system structure is preserved at the closed loop level and the \\
\hline Six phase induction motor & $\begin{array}{l}\text { closed loop energy function is equal to the difference between the physical } \\
\text { energy of the system and the energy supplied by the controller. The proposed } \\
\text { control design is based on combination PCH and BS techniques improve } \\
\text { significantly performance and robustness. The proposed speed control } \\
\text { scheme is validated by Matlab-Simulink software. }\end{array}$ \\
\hline
\end{tabular}

This is an open access article under the CC BY-SA license.

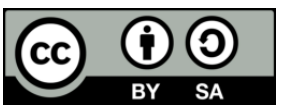

\section{Corresponding Author:}

Ngoc Thuy Pham,

Department of Electrical Engineering Technology,

Industrial University of Ho Chi Minh City,

12 Nguyen Van Bao, Phrong 4, Go Vap, Ho Chi Minh 71406, Vietnam.

Email: ngocpham1020@gmail.com

\section{INTRODUCTION}

In recent decades, the multiphase motor drives are widely used in much applications due to their inherent features such as higher torque density, the rotor harmonic current and torque ripple are smaller, the stator copper loss reduce, the current stress in the semiconductor switching devices reduce proportionally with the number of the motor phase [1]. These multiphase motor drives are often considered in the high power applications such as automotive, aerospace, military and nuclear, locomotive traction, electrical ship propulsion, Besides, the multiphase motors work very reliably and has high fault tolerance so these motor are even considered in the applications requiring small power, the high reliability and fault tolerance. With these motors, when are lost one or more phases they can still provide significant electromagnetic torque to continue the motor drive operation. Among many types of multi-phase motors, SPIM is one of the most widely used multi-phase motors [2].

As the three-phase induction motor, when uncertainties and disturbances are appreciable, traditional control techniques using PID control for SPIM drives are not able to guarantee optimal performance. To overcome these drawbacks the nonlinear control techniques have been followed, such as, for instance, linear 
output feedback control [3, 4], Sliding mode (SM) [5-7], Backstepping control (BS) [8-12], Fuzzy Logic (FL) control [13-14] neural networks (NN) control [15-17], predictive control, [18], Hamiltonian control [19-24]. Among these techniques, the BS is one of the most concerned techniques due to its systematic and recursive design methodology for nonlinear feedback control. BS can be used to force a nonlinear system to behave like a linear system in a new set of coordinates. Beside the advantages such as the flexibility to retaining the useful nonlinearities and effectively pursuing stable and tracking goals, the best major disadvantages of BS technique are the detailed and accurate informations about system dynamics to be required when designing traditional BS. To overcome this drawback many strategies have been proposed, in [25] the authors proposed a new BS control scheme using a dynamical motor model with the unknown of the damping coefficient, motor inertia, load torque and the uncertainty of machine parameters. The tests carried out without applying a load torque.

However, the performance of the tracking the reference speed and the rotor speed ripple are not good, and this proposal also does not eliminate completely the load torque disturbance. In [26, 27], new BS technique was proposed to both the control and speed estimator. Due to increased system state number so this proposal gives better results, but it also makes increasing the calculation effort and time for the processor. In [10] proposed a BS design method for both the control and observer, by adding the integral error tracking component to increase the stability of the transmission system, this method for good dynamic response, precise controls. However, the torque ripple is recorded as quite large, the performance at low speed range and regenerating modes not reported in [10]. From the above analysis it is easy to see that the BS control was difficult to obtain satisfactory control performance when using independently, especially in the cases applied to control the nonlinear systems. Therefore, to solve this problem, beside continue to improve BS strategy, another approach has concentrated to the composite control strategy combining BS method with other control methods, such as sliding mode (SM) control [28-30], neuron network (NN) [31-35], fuzzy logic system (FLS) $[36,37]$. In this paper, the author proposes a new combined control structure: The BS controller is applied in outer speed closed loop control, the BS-based controller design with the integral error tracking component added to improve its sustainability. In addition, to further enhance the SPIMD performance, the authors proposed a new structure combining $\mathrm{BS}$ and $\mathrm{PCH}$, a proposed $\mathrm{PCH}$ for inner current control loop to improve performance and ensure the stability, accuracy speed response for the drive system, enhance the robustness for the sensitivity of changes in machine parameters, load disturbance. The effectiveness of this proposed control structure is verified through MATLAB/ Simulink.

The paper includes five sections, the model of the SPIM and the SPIM drives are presented in section 2. Section 3 presents the BS_PCH controller. The simulation results and discuss are given in Section 4, and the concluding is presented in Section 5.

\section{MODEL OF SPIM DRIVES}

The system includes the six-phase induction motor fed by a six-phase Voltage Source Inverter (SPVSI) and a DC link. A diagram of the SPIMD is illustrated as in Figure 1. In this part, the Vector Space Decomposition (VSD) technique also has applied as in [18], the original six-dimensional space of the machine is transformed int three two-dimensional orthogonal subspaces in the stationary reference frame (D-Q), ( $\mathrm{x}-\mathrm{y})$ and ( $\mathrm{zl}-\mathrm{z} 2)$. This transformation is obtained by means of 6 x 6 transformation matrix [2].

$$
T_{6}=\frac{1}{3}\left[\begin{array}{cccccc}
1 & \frac{\sqrt{3}}{2} & -\frac{1}{2} & -\frac{\sqrt{3}}{2} & -\frac{1}{2} & 0 \\
0 & \frac{1}{2} & \frac{\sqrt{3}}{2} & \frac{1}{2} & -\frac{\sqrt{3}}{2} & -1 \\
1 & -\frac{\sqrt{3}}{2} & -\frac{1}{2} & \frac{\sqrt{3}}{2} & -\frac{1}{2} & 0 \\
0 & \frac{1}{2} & -\frac{\sqrt{3}}{2} & \frac{1}{2} & \frac{\sqrt{3}}{2} & -1 \\
1 & 0 & 1 & 0 & 1 & 0 \\
0 & 1 & 0 & 1 & 0 & 1
\end{array}\right]
$$

To build SPIM model, some basic assumptions should be made. First, the windings are seen as to be sinusoidal distribution, the mutual leakage inductances, the magnetic saturation, and the core losses are neglected. The math equations of SPIM be written in the stationary reference frame as

$$
\begin{aligned}
{\left[V_{s}\right] } & =\left[R_{s}\right]\left[I_{s}\right]+P\left(\left[L_{s}\right]\left[I_{s}\right]+\left[L_{m}\right]\left[I_{r}\right]\right) \\
0 & =\left[R_{r}\right]\left[I_{r}\right]+P\left(\left[L_{r}\right]\left[I_{r}\right]+\left[L_{m}\right]\left[I_{s}\right]\right)
\end{aligned}
$$


where: [V], [I], [R], [L] and [Lm] are voltage, current, resistant, self and mutual inductance vectors, respectively. $\mathrm{P}$ is differential operator. Subscript $\mathrm{r}$ and $\mathrm{s}$ related to the rotor and stator resistance respectively. Since the rotor is squirrel cage, $[\mathrm{Vr}]$ is equal to zero. The electromechanical energy conversion only takes place in the DQ subsystem. The torque equation can be written as follows:

$$
T_{e}=3 n_{p}\left(\psi_{r Q} i_{r D}-\psi_{r D} i_{r Q}\right)
$$

where: respectively, $\mathrm{T}_{\mathrm{e}}, \mathrm{n}_{\mathrm{p}}, \Psi_{\mathrm{rD}}, \Psi_{\mathrm{rQ}}, \mathrm{i}_{\mathrm{rD}}, \mathrm{i}_{\mathrm{rQ}}$ are the electromagnetic torque that generated by the motor, number of pairs of poles, the rotor flux, rotor current, respectively.

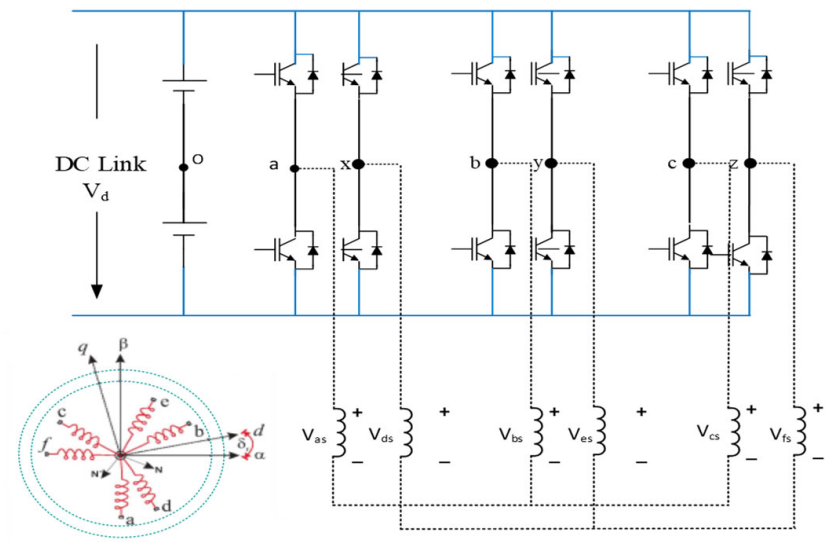

Figure. 1. A SPIM drive general diagram

As you knew, (x - y) and (zl -z2) subspace produced losses, the electromechanical conversion just takes place in the D-Q subspace [2]. Therefore, the control is based on determining the applied voltage in the DQ reference coordinates. Then the SPIM control technique is similar to the classical three phase induction motor. The control for the motor in the stationary reference coordinates is difficult, even for a three phase IM, so the transformation of SPIM model in a dq rotating reference coordinates to obtain currents with dc components is necessary, a transformation matrix must be used to represent the stationary reference coordinates (DQ) in the dynamic (dq) rotating reference coordinates. This matrix is given

$$
T_{d q}=\left[\begin{array}{cc}
\cos \left(\delta_{r}\right) & -\sin \left(\delta_{r}\right) \\
\sin \left(\delta_{r}\right) & \cos \left(\delta_{r}\right)
\end{array}\right]
$$

where $\delta r$ is the rotor angular position referred to the stator as shown in Figure 1.

FOC is one of the most common control methods, Unlike the scalar control, FOC can improve the static and dynamic behavior of SPIM. FOC control can control torque and magnetic flux separately as the control way to DC motor. In that, the electromagnetic torque will be controlled by the isq stator current component, the rotor flux will be controlled by the isd stator current component. We have:

$$
\psi_{r q}=0 ; \psi_{r d}=\psi_{r d}
$$

Using (1) and (4), the new dynamics model of motor is described by the space vector differential equations

$$
\left\{\begin{array}{l}
\frac{d \omega}{d t}=\frac{3}{2} n_{p} \frac{\delta \sigma L_{s}}{J}\left(\psi_{r d} i_{s Q}\right)-\frac{T_{L}}{J}-B \omega \\
\frac{d \psi_{r d}}{d t}=\frac{L_{m}}{\tau_{r}} i_{s D}-\frac{1}{\tau_{r}} \psi_{r d} \\
L_{s} \frac{d i_{s D}}{d t}=-a i_{s D}+L_{s} \omega_{s} i_{s Q}+b R_{r} \psi_{r d}+c u_{s D} \\
L_{s} \frac{d i_{s Q}}{d t}=-a i_{s Q}+L_{s} \omega_{s} i_{s D}+b_{r} \omega_{r} \psi_{r d}+c u_{s Q}
\end{array}\right.
$$


Where, $\sigma=1-\frac{L_{m}^{2}}{L_{s} L_{r}} ; \delta=\frac{L_{m}}{\sigma L_{s} L_{r}} ; a=\frac{L_{m}^{2} R_{r}+L_{r}^{2} R_{s}}{\sigma L_{r}^{2}} ; c=\frac{1}{\sigma} ; b=\frac{L_{m}^{2} R_{r}}{\sigma L_{r}^{2}}$

The electromagnetic torque and the sliding frequency are expressed as follows

$$
\begin{aligned}
& T_{e}=\frac{3}{2} n_{p} \frac{L_{m}}{L_{r}} \psi_{r} i_{s Q} \\
& \omega_{s l}=\frac{L_{m}}{L_{r}} \psi_{r} i_{s Q}
\end{aligned}
$$

\section{THE PROPOSED BS PCH COTROLLER FOR VECTOR CONTROL OF SPIM DRIVES} 3.1. The proposed $B S$ controller for outer speed control and rotor flux loops

The purpose of this study is to design a simple control law but for high dynamic and establishing performance, eliminating load disturbance and effect of motor parameter variations. The influence from the motor parameter variations and the load torque disturbances are significantly reduced when adding a tracking error integration into the BS speed controller design and update the rotor resistance for BS control. BS techniques are a systematic and recursive method for synthesizing nonlinear control rules. The performance and stability of SPIM drives are ensured according to Lyapunov theory [2]. During the design process, each step will have virtual commands created to ensure the convergence of the subsystem. As rotor flux and speed are the tracking objectives, the tracking errors is defined as

$$
\begin{aligned}
& \varepsilon_{\omega}=\omega^{*}-\omega+k_{\omega}^{\prime} \int_{0}^{t \int}\left(\omega^{*}-\omega\right) d t \\
& \varepsilon_{\psi}=\psi_{r d}^{*}-\psi_{r d}+k_{\psi}^{\prime} \int_{0}^{t \int}\left(\psi_{r d}^{*}-\psi_{r d}\right) d t
\end{aligned}
$$

The error dynamical equations are

$$
\begin{aligned}
& \dot{\varepsilon_{\omega}}=\dot{\omega}^{*}-\frac{3}{2} n_{p} \frac{\delta \sigma L_{s}}{J} \psi_{r d} i_{s q}+\frac{T_{l}}{J}+B \omega+k_{\omega}^{\prime}\left(\omega^{*}-\omega\right) \\
& \dot{\varepsilon_{\psi}}=\dot{\psi}_{r d}^{*}-\frac{L_{m}}{\tau_{r}} i_{s d}+\frac{1}{\tau_{r}} \psi_{r d}+k_{\psi}^{\prime}\left(\psi_{r d}^{*}-\psi_{r d}\right)
\end{aligned}
$$

The Lyapunov function is defined as

$$
V_{(\omega, \psi)}=\frac{1}{2}\left(\varepsilon_{\omega}^{2}+\varepsilon_{\psi}^{2}\right)
$$

Differentiating $V$

$$
\begin{aligned}
& \dot{V}_{(\omega, \psi)}=\varepsilon_{\omega} \dot{\varepsilon}_{\omega}+\varepsilon_{\psi} \dot{\varepsilon_{\psi}}=\varepsilon_{\omega}\left[\dot{\omega}^{*}-k_{t} \psi_{r d} i_{s q}+\frac{T_{l}}{J}+B \omega+k_{\omega}^{\prime}\left(\omega^{*}-\omega\right)\right] \\
& +\varepsilon_{\psi_{r d}}\left\{\psi_{r d}^{*}-\frac{L_{m}}{\tau_{r}} i_{s d}^{*}+\frac{1}{\tau_{r}} \psi_{r d}+k_{\psi}^{\prime}\left(\psi_{r d}^{*}-\psi_{r d}\right)\right\}
\end{aligned}
$$

where:

$k_{t}=\frac{3}{2} n_{p} \frac{\delta \sigma L_{s}}{J}, \mathrm{k}_{\omega}, \mathrm{k}_{\Psi}$ are always positive design constants determining the dynamics of closed loop. To $\mathrm{V}^{\prime}$ $<0$, the current stabilizing virtual commands are chosen

$$
\begin{aligned}
& i_{s q}^{*}=\frac{1}{k_{t} \psi_{r d}}\left\{k_{\omega} \varepsilon_{\omega}+\omega^{*}+B \omega+\frac{T_{l}}{J}+k_{\omega}^{\prime}\left(\omega^{*}-\omega\right)\right\} \\
& i_{s d}^{*}=\frac{\tau_{r}}{L_{m}}\left\{k_{\psi} \varepsilon_{\psi}+\psi_{r d}^{*}+\frac{1}{\tau_{r}} \psi_{r d}+k_{\psi}^{\prime}\left(\psi_{r d}^{*}-\psi_{r d}\right)\right\}
\end{aligned}
$$

We obtain

$$
\dot{V}_{(\omega, \psi)}=-k_{\omega} \varepsilon_{\omega}^{2}-k_{\psi} \varepsilon_{\psi}^{2}<0
$$

The selected virtual stator current components in (12) are to satisfy the control objectives in the outer loop and they also are used as references values provided to next inner loop when designing the PCH controller. Eq. (12) can be expressed as Figure 2.

Int J Pow Elec \& Dri Syst, Vol. 11, No. 2, June 2020 : $1099-1108$ 

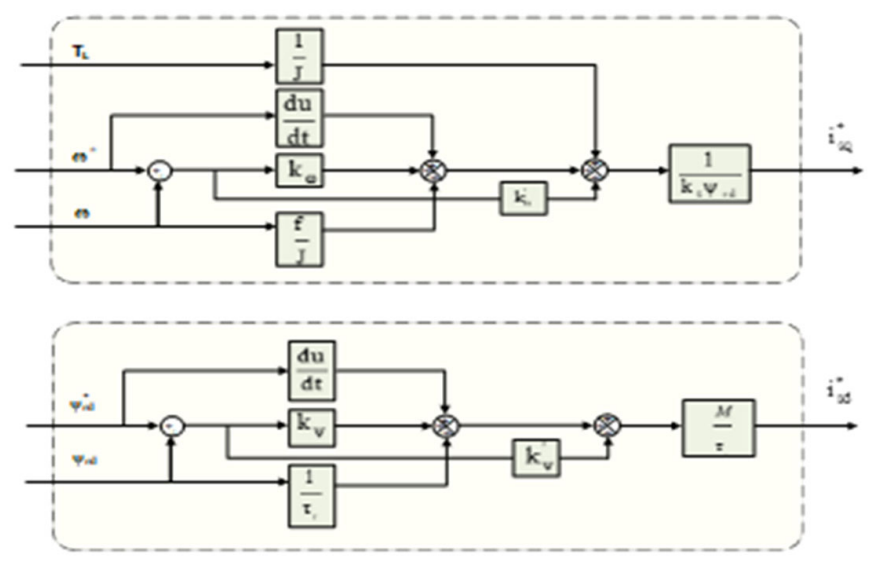

Figure 2. The virtual inputs isq and isd

\subsection{The inner current loop controllers using PCH}

A PCH system with dissipation is a representation of the form:

$$
\left\{\begin{array}{l}
\frac{d x}{d t}=[J(x)-R(x)] \frac{d H}{d x}(x)+g(x) u \\
y=g^{T}(x) \frac{d H}{d x}(x)
\end{array}\right.
$$

where $R_{x}=R_{x}^{T}>0$ represents the dissipation. The interconnection structure is captured in matrix $g(x)$ and the skew symmetric matrix $J_{x}=-J_{x}^{T}, H(x)$ is the total stored energy function of the system. The state vectors, input and output vectors are defined as follows, respectively

$$
\left\{\begin{array}{l}
x=\left[\begin{array}{ll}
x_{1} & x_{2}
\end{array}\right]^{T}=\left[\begin{array}{ll}
L_{s} i_{s d} & L_{s} i_{s q}
\end{array}\right]^{T} \\
u=\left[\begin{array}{ll}
u_{1} & u_{2}
\end{array}\right]^{T} \text { with: } u_{1}=b R_{r} \psi_{r d}+c u_{s d} ; u_{2}=-b \omega_{r} \psi_{r d}+c u_{s q} \\
y=\left[\begin{array}{ll}
i_{s d} & i_{s q}
\end{array}\right]^{T}
\end{array}\right.
$$

The Hamiltonian function of the system is given by

$$
H(x)=\frac{1}{2} x^{T} D^{-1} x=\frac{1}{2}\left(x_{1}^{2}+x_{2}^{2}\right)=\frac{1}{2}\left(L_{s} i_{s d}^{2}+L_{s} i_{s q}^{2}\right) ; \text { where, } D=\operatorname{diag}\left\{L_{s} L_{s}\right\}
$$

Equations of the SPIM described in the dq reference frame (5) can be rewritten in the PCH form (14) with:

$$
\left\{\begin{array}{l}
J(x)=\left[\begin{array}{cc}
0 & L_{s} \omega_{s} \\
-L_{s} \omega_{s} & 0
\end{array}\right] \\
R(x)=\left[\begin{array}{ll}
a & 0 \\
0 & a
\end{array}\right] ; \quad g(x)=\left[\begin{array}{ll}
1 & 0 \\
0 & 1
\end{array}\right]
\end{array}\right.
$$

Suppose that with the expectation of systematic stability (19) around a desired equilibrium xo, a $\mathrm{Hd}$ (x) closed-loop energy function, which has a strict minimum at $\mathrm{x} 0$ (that is, $\mathrm{Hd}(\mathrm{x})>\mathrm{Hd}(\mathrm{x} 0)$ for all $\mathrm{x}$, is assigned to the system. The feedback stabilization theory of PCH system is given as follows [6]. Given J(x), $\mathrm{R}(\mathrm{x}), \mathrm{H}(\mathrm{x}), \mathrm{g}(\mathrm{x})$ and the desired equilibrium $\mathrm{xo}$. Then a feedback control $\mathrm{u}=\alpha(\mathrm{x}), \mathrm{R}_{\mathrm{a}}(\mathrm{x}), \mathrm{J}_{\mathrm{a}}(\mathrm{x})$ and $\mathrm{K}(\mathrm{x})$ vector functions can be found and they satisfy

$$
\left[J_{d}(x)-R_{d}(x)\right] K(x)=-\left[J_{a}(x)-R_{a}(x)\right] \frac{d H}{d x}(x)+g(x) u
$$

That is 


$$
\frac{d K}{d x}(x)=\left[\frac{d K}{d x}(x)\right]^{T} ; K\left(x_{0}\right)=-\frac{d H}{d x}\left(x_{0}\right) ; \frac{d K}{d x}\left(x_{0}\right)>\frac{d^{2} H}{d^{2} x}\left(x_{0}\right)
$$

The closed loop system as fellow

$$
\frac{d x}{d t}=\left[J_{d}(x)-R_{d}(x)\right] \frac{d H_{d}}{d x}(x)
$$

This system will be a dissipation PCH system

$$
K(x)=\frac{d H_{a}}{d x} ; H_{a}(x)=H_{d}(x)-H(x)
$$

where, Ha is an added energy into the system for this closed-loop system is gained a stable equilibrium at $\mathrm{x} 0$. Then expected Hamiltonian energy storage function is defined as

$$
H_{d}(x)=H(\tilde{x}) \quad \text { with }: \quad \tilde{x}=x-x_{0}
$$

Where,

$$
\begin{aligned}
& J_{d}(x)=J(x)+J_{a}(x)=-J_{d}^{T}(x) ; R_{d}(x)=R(x)+R_{a}(x)=R_{d}^{T}(x)>0 \\
& J_{a}(x)=\left[\begin{array}{cc}
0 & J_{1} \\
-J_{1} & 0
\end{array}\right] ; R_{a}(x)=\left[\begin{array}{cc}
r_{1} & 0 \\
0 & r_{2}
\end{array}\right]
\end{aligned}
$$

where, $\mathrm{J} 1$ is interconnect parameter, $\mathrm{r} 1$, and $\mathrm{r} 2$ are damping parameters and From (17) to (22), the control components of the current controller in the inner loop is determined as

$$
\left\{\begin{array}{l}
u_{s d}=\sigma\left[a i_{s d}^{*}+r_{1}\left(i_{s d}^{*}-i_{s d}\right)-J_{1}\left(i_{s q}^{*}-i_{s q}\right)-L_{s} \omega_{s} i_{s q}^{*}-b R_{r} \psi_{r d}\right] \\
u_{s q}=\sigma\left[a i_{s q}^{*}+r_{2}\left(i_{s q}^{*}-i_{s q}\right)+J_{1}\left(i_{s d}^{*}-i_{s d}\right)+L_{s} \omega_{s} i_{s d}^{*}+b \omega_{r} \psi_{r d}\right]
\end{array}\right.
$$

In (12) and (24), the rotor flux value which cannot be measured is in identified by VM and is presented in section 2.3. A new control structure combinating BS_PCH for FOC of the SPIM drive be expressed as Figure 3.

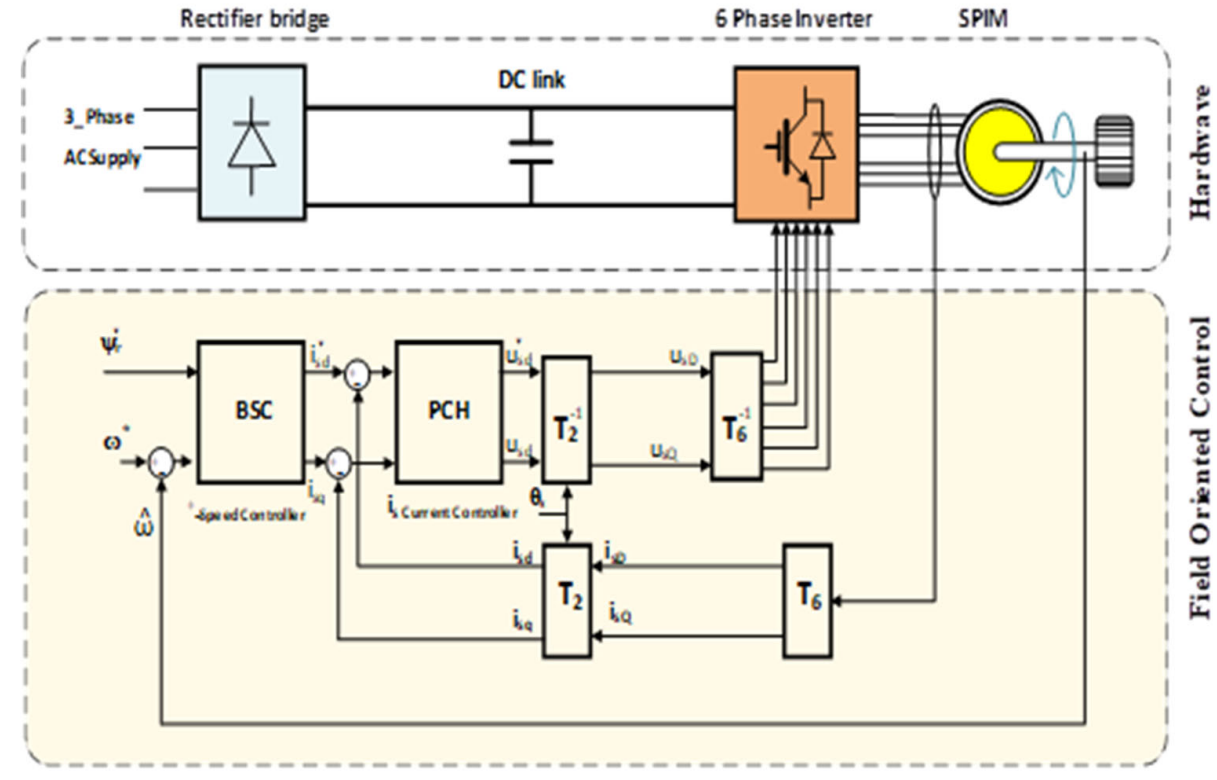

Figure 3. FOC technique of the SPIM drive with BS_PCH controller 


\section{SIMULINK AND DISCUSSION}

In this part, the performance verification of BS_PCH cotrol scheme for FOC technique of SPIM drive as shown in Figure 3 is carried out through Matlab simulation software. SPIM drive with the proposed control scheme has been surveyed at different working speed areas. These surveys are implemented based benchmark tests in [15], [17]. SPIM parameters: $1 \mathrm{HP}, 220 \mathrm{~V}, 50 \mathrm{~Hz}, 4$ pole, $1450 \mathrm{rpm}$. Rs $=10.1 \Omega, \mathrm{Rr}=$ $9.8546 \Omega, \mathrm{Ls}=0.833457 \mathrm{H}, \mathrm{Lr}=0.830811 \mathrm{H}, \mathrm{Lm}=0.783106 \mathrm{H}, \mathrm{Ji}=0.0088 \mathrm{~kg} \cdot \mathrm{m} 2 . \mathrm{Rs}$ is nominal value of stator resistance.

Test 1: Tracking Reference

Test 1 is carried out according recommended Benchmark tests in [15]. In that, the reference speed is set up from $65 \mathrm{rad} / \mathrm{s}$ to $125 \mathrm{rad} / \mathrm{s}$ at $3 \mathrm{~s}, 50 \%$ rated load applied at $6 \mathrm{~s}$. The results in Figure 4(a) shows the tracking reference performance of the BS_PCH scheme based on vector control is very well. Comparing to PI controller and NN controller in [15], it is easy to see that the BS PCH controller give responses faster, more accurate and better the tracking reference performance than PI controller and NN controller. The results in Figure 4(a) also show that the stator current and torque response, which provided by $\mathrm{PCH}$ vector control, is fewer oscillations than both the conventional and $\mathrm{NN}$ vector control in [15]. In order to assess the robustness for load disturbance of the proposed BS_PCH control, observing the speed response in Figure 4(a) at 6s when load torque is applied, we see that error in tracking the speed increase not significantly at $6 \mathrm{~s}$, the real speed instantly converges to the reference speed. For test in [15], the error in tracking the speed reference appear in both conventional vector control and $\mathrm{NN}$ vector control, these errors in tracking the speed reference are higher than that appeared in BS_PCH vector control scheme.

Test 2: Detuning Effects

This test is implemented to evaluate the proposed BS PCH control performance under motor parameter variation condition and load disturbance. The extreme conditions are surveyed with the rotor resistance value was setup increased $\mathrm{Rr}^{\prime}=3 \mathrm{Rr}$ at $2.5 \mathrm{~s}$, the reference speed is increased from $65 \mathrm{rad} / \mathrm{s}$ up to $125 \mathrm{rad} / \mathrm{s}$ at $3 \mathrm{~s}, 50 \%$ rated load applied at $6 \mathrm{~s}$. Figure 4(b) shows the speed, torque and current responses of the proposed BS_PCH vector control scheme, respectively.
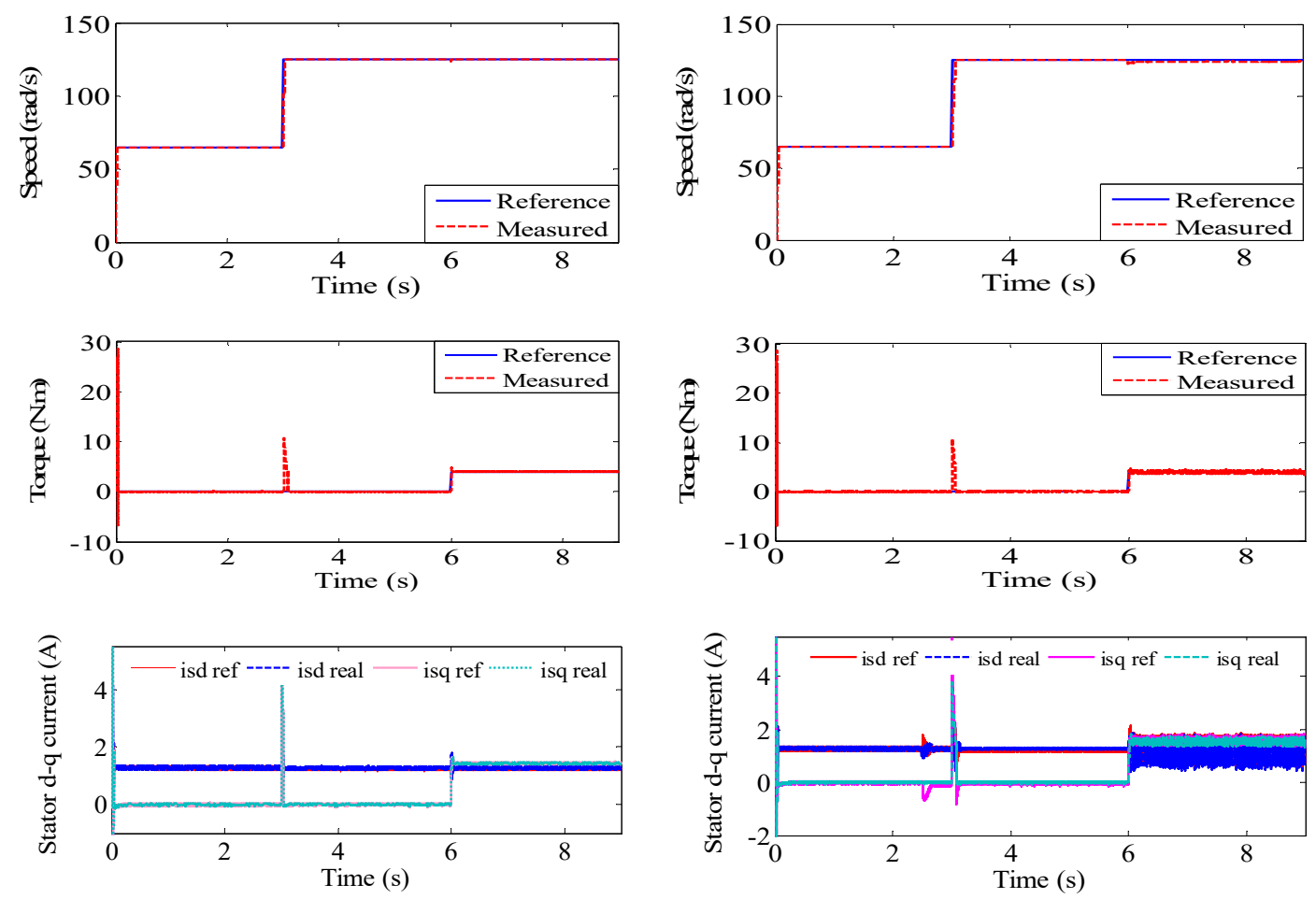

(a)

(b)

Figure 4. BS_PCH vector control with setting: a. Nominal rotor resistance; $b . \mathrm{Rr}^{*}=3 \mathrm{Rr}$ 
These survey results show that the PCH control scheme can provide the performance well when facing the parameter variations and load torque disturbance. The speed and current responses are almost unaffected until 50\% rated load has been applied to motor. When applying load, error speed tracking and ripple current and torque increased slightly. However, comparing to $\mathrm{NN}$ control in and conventional PI control in [15], it is easy to see that BS_PCH scheme give better performance, more robustness for the uncertain motor parameter of and load disturbance. The results in Figure 4(b) show that the torque and current oscillations of the proposed scheme in this paper less than the conventional PI vector control and NN control in [15]. The PCH scheme handle current loops quite efficiently, the compensation function Ha added to keep system always work stably at reference values. $i_{\text {sd }}$, $i_{\text {sq }}$ stator current responses in extreme condition $\mathrm{Rr}$ increased $300 \%, 50 \%$ rated load are better than NN control [15].

\section{Test 3}

In Test 3, two cases are examined based on recommend [17].

Case 1, the reference speed changes without load, the results are shown in Figure 5.

Case 2 , the speed is fixed at $1000 \mathrm{rpm}$ during the survey time, the load torque of $100 \%$ is rated at $7 \mathrm{~s}$ (instead of $75 \%$ rated load as [17]), the results are shown in Figure 6.

From the simulation results, it is easy to see that the dynamic performance of the BS_PCH controller is very good. It does not appear the speed and current ripple, the controlled value converges and follow very rapidly the reference value during the survey period (Figure 5, Figure 6). The convergence time of the speed is significantly improved compared to the controller proposed in [17]. On the other hand, when observing effect of the load disturbance at 7s in case 2 (Figure 6 at 7s), it is easy to see its robustness to load disturbances, there is no oscillation or significant speed reduction recorded, compared to the traditional PI controller and the controller proposed in [17], the SM_FL controller is proposed) in [17] to handle better load disturbance, however, the load disturbance still make reduce the speed at $7 \mathrm{~s}$ then the motor speed converges with a stable reference value.
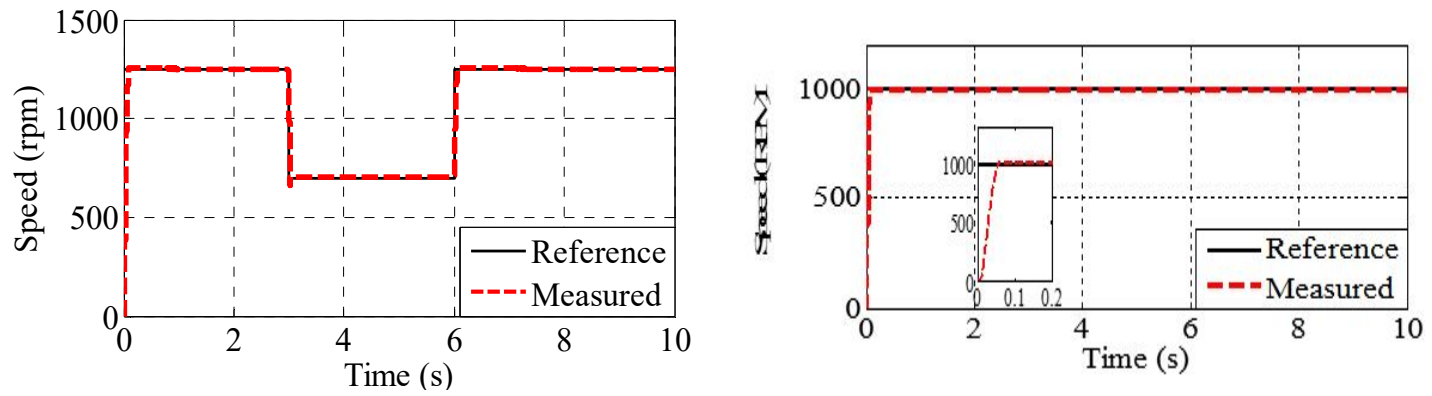

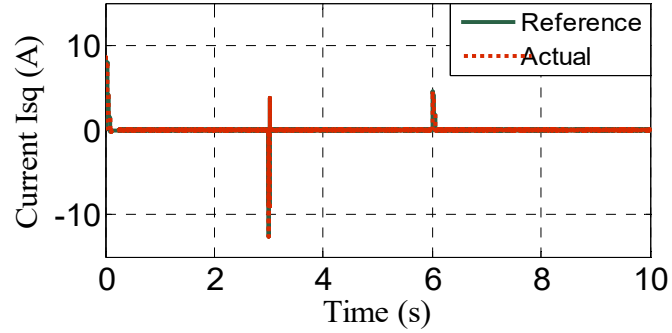

Figure 5. The speed and torque responses in case of speed variations without load

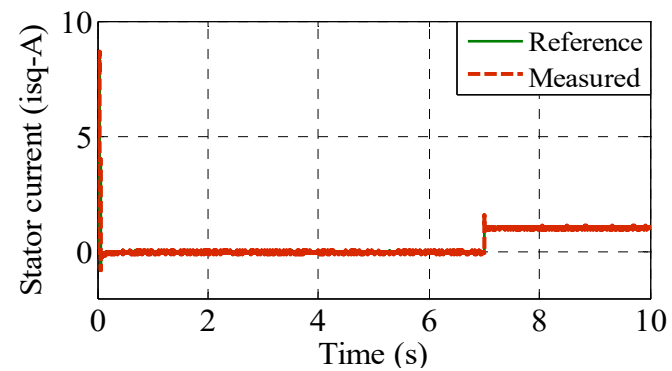

Figure. 6 The speed and torque responses in case of constant speed

\section{CONCLUSION}

This paper presents a new approach to FOC control of SPIM. Two nonlinear controllers, one of Backstepping control (BSC) and the other Port Controlled Hamiltonian (PCH) define a new control structure for vector control of SPIM drive systemt, enables very good static and dynamic performance of SPIM drives (perfect tuning of the speed reference values, fast response of the motor current and torque, high accuracy of speed regulation), and robust for the machine parameter variations, load disturbances. The simulation results 
and discussion in section 4 confirmed the good dynamics and robustness of the proposed control algorithm based on the BS_PCH.

\section{REFERENCES}

[1] E. Levi, "Multiphase electric machines for variable-speed applications," IEEE Transactions on Industrial Electronics, Vol. 55, No. 5,pp. 1893 - 1909, 2008.

[2] Ngoc Thuy Pham, Diep Phu Nguyen, Khuong Huu Nguyen, and Nho Van Nguyen, "A Novel Neural Network SC MRAS Based Observer for High-Performance," International Journal of Intelligent Engineering and Systems, Vol. 11, No. 6, pp. 95-107, 2018.

[3] F. Alonge, M. Cirrincione, M. Pucci, and A. Sferlazza, "Input-Output Feedback Linearization Control With OnLine MRAS-Based Inductor Resistance Estimation of Linear Induction Motors Including the Dynamic End Effects," IEEE Transactions on Industry Applications, Vol. 52, No. 1, pp. 254-266, 2016

[4] Hamou Ait Abbasa, Mohammed Belkheirib, Boubakeur Zegninia, "Feedback Linearization Control of An Induction Machine Augmented by Single Hidden Layer Neural Networks," International Journal of Control, Vol. 89, No. 1, pp. 140-155, 2016.

[5] Abdelmadjid Boumedienne and Hachemi Glaoui, "Sliding Mode Backstepping Control of Induction Motor Othmane Boughazi," International Journal of Power Electronics and Drive System (IJPEDS), Vol. 4, No. 4, pp. 481-488, 2014.

[6] Gouichiche Abdelmadjid, Boucherit Mohamed Seghir, Safa Ahmed, and Messlem Youcef, "Sensorless Sliding Mode Vector Control of Induction Motor Drives," International Journal of Power Electronics and Drive System (IJPEDS), Vol. 2, No. 3, pp. 277-284, 2012.

[7] Tohidi, A., Shamsaddinlou, A., and Sedigh, A.K., "Multivariable input-output linearization sliding mode control of DFIG based wind energy conversion system," 9th Asian Control Conf. (ASCC), Istanbul, Turkey, pp. 1-6, 2013.

[8] Y. Tan, J. Chang, and H. Tan, "Adaptive back-stepping control and friction compensation for AC servo with inertia and load uncertainties," IEEE Transactions on Industrial Electronics, vol. 50, pp. 944-952, 2003.

[9] M.R Jovanovic and B. Bamieh, "Architecture Induced by Distributed Backstepping Design," IEEE Transactions on Automatic Control, Vol. 52, No. 1, pp. 108 - 113, 2007.

[10] Abderrahmen Zaafouri, Chiheb Ben Regaya, Hechmi Ben Azza, and Abdelkader Châari, "zDSP-based adaptive backstepping using the tracking errors for high-performance sensorless speed control of induction motor drive," ISA Transactions, Vol. 60, pp. 333-347, 2016.

[11] Traoré D, De Leon J, and Glumineau A, "Sensorless induction motor adaptive observer-backstepping controller: experimental robustness tests on low frequencies benchmark," IET Control Theory, Vol. 48, No. 11, pp. 1989-2002, 2010.

[12] Morawiec M., "Z type observer backstepping for induction machines," IEEE Trans Ind Electron, Vol. 99, No. 1, 2014.

[13] R. Gunabalan and V. Subbiah, "Speed Sensorless Vector Control of Induction Motor Drive with PI and Fuzzy Controller," International Journal of Power Electronics and Drive System (IJPEDS), Vol. 5, No. 3, pp. 315-325, February 2015.

[14] Ahmed J. Ali1, Ziyad K. Farej, and Nashwan S. Sultan, "Performance evaluation of a hybrid fuzzy logic controller based on genetic algorithm for three phase induction motor drive," International Journal of Power Electronics and Drive System (IJPEDS), Vol. 10, No. 1, pp. 117-127, March 2019.

[15] Xingang $\mathrm{Fu}$ and Shuhui $\mathrm{Li}$, "A Novel Neural Network Vector Control Technique for Induction Motor Drive," IEEE Transactions on Energy Conversion, Vol.30, No. 4, pp. 1428-1437, 2015.

[16] Nasir Uddin M. Huang Z. R.; Siddique Hossain A. B. M., "Development and Implementation of a Simplified SelfTuned Neuro-Fuzzy Based IM Drive," J. Sci. IEEE Transactions on Industry Applications, Vol. 50, No. 1, pp. 51-59, 2014.

[17] Ashutosh Mishra and Prashant Choudhary, "Artificial Neural Network Based Controller for Speed Control of an Induction Motor using Indirect Vector Control Method," International Journal of Power Electronics and Drive System (IJPEDS), Vol. 2, No. 4, pp. 402-408, December 2012.

[18] Ying Liu, Shanmei Cheng, Bowen Ning, and Yesong Li, "Performance enhancement using durational model predictive control combined with backstepping control and disturbance observer for electrical drives," Journal of Vibration and Control, Vol. 2, No. 4, pp. 402-408, Vol. 25, No.2, October 2018.

[19] C. Cecati, "Position control of the induction motor using a passivitybased Controller," IEEE Transactions on Industry Applications, Vol. 36, pp. 1277-1284, 2000.

[20] H. Yu, K. Zhao, H. Wang, and L. Guo, "Energy shaping control of PM synchronous motor based on load torque observer," Systems Engineering and Electronics, vol. 28, no. 11, pp. 1740-1742, 2006.

[21] H. YU, K. Zhao, L. Guo, and H. Wang, "Maximum Torque Per Ampere Control of PMSM Based on Port-controlled Hamiltonian Theory," Proceedings of the CSEE, Vol. 26, No.8, pp. 82-87, May 2006.

[22] Zhiping Cheng and Liucheng Jiao, "Hamiltonian Modeling and Passivity-based Control of Permanent Magnet Linear Synchronous Motor," Journal Of Computers, Vol. 8, No. 2, February 2013.

[23] Van der Schaft, Arjan, "L2-Gain and Passiving Techniquess in Nonlinear Control," London Springer-Verlag, 2000.

[24] Ortega R., Vander Scjhaftb A.J, Mareels, etal. "Interconnection and damping assignment passivity-based contron of port-controlled Hamiltionian systems," Automatica, Vol. 38, No. 4, pp. 585-596, 2002.

[25] Hou-Tsan Lee, Fu Li-Chen, and Lian Feng-Li, "Sensorless adaptive backstepping speed control of induction motor," Proceedings of the 45th IEEE conference on decision and control, USA; pp. 1252-57, 2006.

Novel nonlinear control structure for vector control of SPIM drive using BS PCH (Ngoc Thuy Pham) 
[26] Mehazzem F, Nemmour AL, Reama A, and Benalla H., "Nonlinear integral backstepping control for induction motors," Proceedings of 2011 international Aegean conference on electrical machines and power electronics and 2011 Electromotion Joint Conference (ACEMP), pp. 331-36, 2011.

[27] Traoré D, De Leon J, Glumineau A., "Sensorless induction motor adaptive observer-backstepping controller: experimental robustness tests on low frequencies benchmark," IET Control Theory Appl, Vol. 48, No. 10, pp.1989-2002, 2010.

[28] J. Liu, S. Vazquez, L. Wu, et al., "Extended state observer-based sliding-mode control for three-phase power converters," IEEE Trans. Ind. Electron., Vol. 64, No. 1, pp. 22-31, 2017.

[29] J. Liu, W. Luo, X. Yang, et al., "Robust model-based fault diagnosis for PEM fuel vell air-feed system," IEEE Trans. Ind. Electron., Vol. 63, No. 5, pp. 3261-3270, 2016.

[30] Q. Su, W. Quan, G. Cai, et al., "Improved adaptive backstepping sliding mode control for generator steam valves of non-linear power systems," IET Control Theory Appl., Vol.11, No. 9, pp. 1414-1419. 2017.

[31] W. Chen, S. Ge, J. Wu, et al., "Globally stable adaptive backstepping neural network control for uncertain strictfeedback systems with tracking accuracy known a priori," IEEE Trans Neural Netw. Learn. Syst, Vol. 26, No. 9, pp. 1842-1854, 2015.

[32] Z. Liu, B. Chen, and C. Lin, "Adaptive neural backstepping for a class of switched nonlinear system without strictfeedback form,” IEEE Trans. Syst. Man Cybern. Syst., Vol. 47, No. 7, pp. 1315-1320, 2017.

[33] Z. Liu, B. Chen, and C. Lin, "Output-feedback control design for switched nonlinear systems: adaptive neural backstepping approach,” Inf. Sci., Vol. 457, pp. 62-75, 2018.

[34] Y. Sun, B. Chen, and C. Lin, "Adaptive neural control for a class of stochastic nonlinear systems by backstepping approach," Inf. Sci., Vol. 369, pp. 748-764, 2016.

[35] J. Yu, B. Chen, H. Yu, et al., "Neural networks-based command filtering control of nonlinear systems with uncertain disturbance," Inf. Sci, Vol. 426, pp. 50-60, 2017.

[36] H. Li, L. Wang, H. Du, et al., "Adaptive fuzzy backstepping tracking control for strict-feedback systems with input delay,” IEEE Trans. Fuzzy Syst., Vol. 25, No. 3, pp. 642-652, 2017.

[37] J. Yu, P. Shi, W. Dong, et al., "Observer and command-filter-based adaptive fuzzy output feedback control of uncertain nonlinear systems," IEEE Trans. Ind. Electron., Vol. 62, No. 9, pp. 5962-5970, 2015.

[38] Abhisek Pal, Sukanta Das, and Ajit K. Chattopadhyay, "An Improved Rotor Flux Space Vector Based MRAS for Field Oriented Control of Induction Motor Drives," IEEE Transactions on Power Electronics, Vol. 33, No. 6, pp. $5131-5141,2018$.

[39] K. J. Astrom and B. Wittenmark, Adaptive Control. New York, NY, USA: Addison-Wesley, 1995.

\section{BIOGRAPHIES OF AUTHOR}

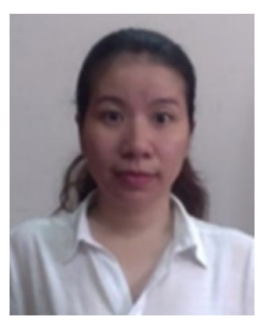

Ngoc Thuy Pham was born in Viet Nam, in 1976. She received the B.Sc degrees in Electrical Engineering from Thai Nguyen University of Technology in 1994, and the M.Sc from Ho Chi Minh City University of Technology in 2009. She has been in the Faculty of Electrical Engineering, Industrial University of Ho Chi Minh City from 2000. Her current research interests include the PWM techniques for power converters, AC motor drives, multiphase induction motor, sensorless control of multiphase induction motor drives 